\title{
Respiratory sinus arrhythmia is reduced after pulmonary vein isolation in patients with paroxysmal atrial fibrillation
}

Christiane Jungen, Fares-Alexander Alken, Christian Eickholt, Katharina Scherschel, Pawel Kuklik, Niklas Klatt, Jana Schwarzl, Julia Moser, Mario Jularic, Ruken Oezge Akbulak, Benjamin Schaeffer, Stephan Willems, Christian Meyer

Department of Cardiology - Electrophysiology University Heart Center, University Hospital Hamburg-Eppendorf, Hamburg, Germany

Submitted: 12 December 2017

Accepted: 11 February 2018

Arch Med Sci 2020; 16 (5): 1022-1030

DOI: https://doi.org/10.5114/aoms.2019.83883

Copyright (c) 2019 Termedia \& Banach

\section{Abstract}

Introduction: Respiratory sinus arrhythmia (RSA) describes heart rate (HR) changes in synchrony with respiration. It is relevant for exercise capacity and mechanistically linked with the cardiac autonomic nervous system. After pulmonary vein isolation (PVI), the current therapy of choice for patients with paroxysmal atrial fibrillation (AF), the cardiac vagal tone is often diminished. We hypothesized that RSA is modulated by PVI in patients with paroxysmal AF.

Material and methods: Respiratory sinus arrhythmia, measured by using a deep breathing test and heart rate variability parameters, was studied in 10 patients ( $64 \pm 3$ years) with paroxysmal AF presenting in stable sinus rhythm for their first catheter-based PVI. Additionally, heart rate dynamics before and after PVI were studied during sympathetic/parasympathetic coactivation by using a cold-face test. All tests were performed within $24 \mathrm{~h}$ before and $48 \mathrm{~h}$ after PVI.

Results: After PVI RSA (E/I difference: $7.9 \pm 1.0$ vs. $3.5 \pm 0.6$ bpm, $p=0.006$; E/I ratio: $1.14 \pm 0.02$ vs. $1.05 \pm 0.01, p=0.003$ ), heart rate variability (SDNN: $31 \pm 3$ vs. $14 \pm 3 \mathrm{~ms}, p=0.006$; RMSSD: $17 \pm 2$ vs. $8 \pm 2 \mathrm{~ms}, p=0.002)$ and the HR response to sympathetic/parasympathetic coactivation $(10.2 \pm 0.7 \%$ vs. $5.7 \pm 1.1 \%, p=0.014$ ) were diminished. The PVI-related changes in RSA correlated with the heart rate change during sympathetic/parasympathetic coactivation before vs. after PVI (E/I difference: $r=0.849, p=0.002$; E/I ratio: $r=0.786, p=0.007$ ). One patient with vagal driven arrhythmia experienced AF recurrence during follow-up (mean: $6.5 \pm 0.6$ months).

Conclusions: Respiratory sinus arrhythmia is reduced after PVI in patients with paroxysmal AF. Our findings suggest that this is related to a decrease in cardiac vagal tone. Whether and how this affects the clinical outcome including exercise capacity need to be determined.

Key words: vagal activity, cold face test, deep breathing test, heart rate variability, exercise, physical fitness.

\section{Introduction}

Respiratory sinus arrhythmia (RSA) describes heart rate (HR) changes in synchrony with respiration, with an increased $H R$ in inspiration and a decreased HR in expiration [1]. First described by Carl Ludwig

\author{
Corresponding author: \\ Dr. Christian Meyer \\ Department of Cardiology \\ - Electrophysiology \\ University Heart Center \\ University Hospital \\ Hamburg-Eppendorf \\ Martinistraße 52 \\ 20246 Hamburg, Germany \\ Phone: +49 1797498380 \\ E-mail: chr.meyer@uke.de
}


more than 150 years ago [2], RSA is caused by phasic changes of efferent vagal neural discharge directed to the sinus node. At rest, RSA is known to improve the efficiency of the pulmonary gas exchange, to reduce variations in blood pressure as well as in cardiac output and further to reduce cardiac energy expenditure [3-5]. In patients with paroxysmal atrial fibrillation (AF), the most common sustained arrhythmia in humans, alterations in $\mathrm{HR}$ variability (HRV), are well known as indicated by HRV time- and frequency-domain analysis [6, 7]. Of interest, RSA has not been studied in patients with symptomatic paroxysmal AF.

A relevant number of patients with paroxysmal AF exhibit reduced physical fitness, which in some patients has been shown to be only partly restored after conversion to sinus rhythm [8]. The current therapy of choice for patients suffering from paroxysmal AF is catheter-based pulmonary vein isolation $(\mathrm{PVI})$. During this procedure vagal intracardiac neurons are inevitably obliterated, leading to a reduced cardiac vagal tone [9]. Transient ( $<6$ months) elevation of HR, inappropriate sinus tachycardia and reduction of HRV have been observed after PVI [10]. Cardiac sympathetic and vagal activation by using the cold face test has been found to be modulated in patients after PVI [11], but its relation with RSA has not been studied so far.

Here, we hypothesized that a decrease in cardiac vagal control following PVI is accompanied by a decrease in RSA in patients with paroxysmal AF.

\section{Material and methods}

\section{Study design and patient selection}

Patients with a history of paroxysmal AF, who were referred for their first PVI, were included. The autonomic etiology of AF was classified as vagal, adrenergic and mixed type [12]. The RSA and HRV were measured prior to ablation and within 24 to $48 \mathrm{~h}$ after ablation. Subjects were advised to refrain from exercise and alcohol ( $>24 \mathrm{~h}$ ) as well as from food intake, nicotine and caffeine (> $4 \mathrm{~h}$ ) prior to testing [13]. Informed consent was obtained from each patient. The following exclusion criteria applied: persistent/long standing persistent AF, arrhythmias during autonomic tests, sick sinus syndrome, unstable angina pectoris, history of myocardial infarction, heart failure, left ventricular ejection fraction $<30 \%$, prior heart surgery, neuromodulation therapy (including electrical stimulation of the spinal cord, vagus nerve stimulation or deep brain stimulation), hyperthyroidism, chronic obstructive pulmonary disease, acute inflammation (C-reactive protein > $5 \mathrm{mg} / \mathrm{l}$ ) and short-term AF recurrence after PVI.

\section{Assessment of HRV and RSA}

Patients rested in a supine position in a quiet, temperature-controlled environment for at least 10 min before testing commenced [13]. A mobile digital HR monitor (Polar Flow V800, Polar Electro Oy, Kempele, Finland) measuring RR intervals with a sample rate of $1000 \mathrm{~Hz}$ was used to record all data. Additionally, a 12-channel electrocardiogram was recorded. Short-term HRV at rest was recorded over a period of $5 \mathrm{~min}$. For RSA assessment a deep breathing test was performed during which patients were guided by an acoustic signal to deeply inhale and exhale for $5 \mathrm{~s}$ each over a period of $60 \mathrm{~s}$ [14]. HRV parameters, the expiratory-inspiratory $H R$ difference (E/I difference) and the expiratory-inspiratory $\mathrm{HR}$ ratio (E/I ratio) were calculated.

The cold face test was conducted to analyze the functional activation of the autonomic nervous system by coactivation of the peripheral sympathetic and cardiac parasympathetic nervous system [15]. Cold gel packs $\left(0^{\circ} \mathrm{C}\right.$ to $\left.1^{\circ} \mathrm{C}\right)$ were applied to the forehead as well as the maxillary region for $120 \mathrm{~s}$ [14], while avoiding ocular contact to prevent the oculocardiac reflex [16]. The maximum $\mathrm{HR}$ response in comparison to the baseline, assessed by the relative difference between baseline HR and peak response as a result of the cold face test, and the time from onset until the maximum response (the maximum latency) were utilized to assess the effect of sympathetic/parasympathetic coactivation [17]. Patients rested for at least 10 min between autonomic maneuvers to prevent interferences. All tests were conducted under standardized surrounding conditions. In case of poor signal quality, outside interference or lack of patient compliance during maneuvers the recordings were not further analyzed.

The HRV was analyzed with the Kubios Software (Version 2.2, Biosignal Analysis and Medical Imaging Group, Department of Physics and Mathematics, University of Eastern Finland) following established protocols [18, 19]. Premature supraventricular and ventricular beats as well as artifacts were extracted to prevent a change and falsification of HR and HRV [19]. The intrinsic HR was assessed using the following formula: intrinsic $\mathrm{HR}=118.1-(0.57 \times$ age $)[20]$.

\section{Catheter ablation}

All patients underwent catheter-based PVI as described before [21]. Deep sedation was achieved by continuous propofol infusion and fentanyl bolus administration throughout the procedure. Surface electrocardiograms and bipolar endocardial electrograms were continuously recorded and stored on a computer-based digital amplifier/recorder system (LabSystem PRO, Bard Electrophysiology Inc., Lowell, MA, USA). Catheters were introduced 
C. Jungen, F.A. Alken, C. Eickholt, K. Scherschel, P. Kuklik, N. Klatt, J. Schwarzl, J. Moser, M. Jularic, R.O. Akbulak, B. Schaeffer, S. Willems, C. Meyer

Table I. Patient characteristics

\begin{tabular}{|c|c|}
\hline Parameter & Value \\
\hline \multicolumn{2}{|l|}{ Patient characteristics: } \\
\hline Age [years] & $64 \pm 3$ \\
\hline Sex (male) & 5 \\
\hline BMI $\left[\mathrm{kg} / \mathrm{m}^{2}\right]$ & $27 \pm 1$ \\
\hline $\mathrm{CHA}_{2} \mathrm{DS}_{2}$-VASc score $0 / 1 / \geq 2$ & $1 / 2 / 7$ \\
\hline EHRA score I/II/III/IV & $1 / 4 / 5 / 0$ \\
\hline \multicolumn{2}{|l|}{ Comorbidities: } \\
\hline Coronary artery disease & 1 \\
\hline Congestive heart failure & 0 \\
\hline Hypertension & 7 \\
\hline Hyperlipidemia & 4 \\
\hline Diabetes mellitus & 1 \\
\hline $\begin{array}{l}\text { Chronic kidney disease } \\
\left(\text { GFR }<60 \mathrm{ml} / \mathrm{min} / 1.73 \mathrm{~m}^{2}\right)\end{array}$ & 0 \\
\hline \multicolumn{2}{|l|}{ Medication before PVI: } \\
\hline $\begin{array}{l}\text { Patients with antiarrhythmic medication } \\
\text { intake }\end{array}$ & 9 \\
\hline \multicolumn{2}{|c|}{ Number of antiarrhythmic agents per patient: $1.2 \pm 0.2$} \\
\hline$\beta$-Blocker & 7 \\
\hline Flecainide & 3 \\
\hline Propafenone & 0 \\
\hline Amiodarone & 1 \\
\hline Dronedarone & 1 \\
\hline Oral anticoagulation & 9 \\
\hline ACE inhibitor/AT-II antagonist & 6 \\
\hline Statin & 3 \\
\hline Diuretics & 1 \\
\hline Oral antidiabetics/insulin & 1 \\
\hline \multicolumn{2}{|l|}{ Pulmonary vein isolation: } \\
\hline Radiofrequency/cryoballoon ablation & $5 / 5$ \\
\hline Procedure duration [min] & $123 \pm 11$ \\
\hline \multicolumn{2}{|l|}{ Follow-up: } \\
\hline Mean follow-up time [days] & $183 \pm 17$ \\
\hline $\begin{array}{l}\text { Patients with antiarrhythmic medication } \\
\text { intake }\end{array}$ & 6 \\
\hline $\begin{array}{l}\text { Number of antiarrhythmic agents per } \\
\text { patient: }\end{array}$ & $0.7 \pm 0.2$ \\
\hline$\beta$-Blocker & 5 \\
\hline Flecainide & 1 \\
\hline Propafenone & 0 \\
\hline Amiodarone & 1 \\
\hline Dronedarone & 0 \\
\hline AF recurrence and re-ablation & 1 \\
\hline EHRA score I/II/III/IV & $9 / 0 / 1 / 0$ \\
\hline
\end{tabular}

Values are mean \pm S.E.M. or $n$. ACE - angiotensin-converting enzyme, AT-II - angiotensin II, BMI - body mass index, EHRA European Heart Rhythm Association, GFR - glomerular filtration rate, $P V I$ - pulmonary vein isolation. via femoral venous access and through a transseptal puncture into the left atrium. A 6-French diagnostic decapolar catheter (Inquiry, $5 \mathrm{~mm}$ spacing; St. Jude Medical, Saint Paul, MN, USA) was placed within the coronary sinus. Esophageal temperature was measured by a multipolar temperature-sensing catheter (CIRCA-S-CATHTM, Circa Scientific, Englewood, CO, USA) and ablation was interrupted when $38.5^{\circ} \mathrm{C}$ was reached. Radiofrequency catheter ablation procedures were guided by 3-dimensional mapping of the left atria using the Carto 3 system (Biosense Webster, Diamond Bar, CA, USA). A decapolar mapping catheter (Lasso, Biosense Webster, Diamond Bar, CA, USA) and an open-irrigated $3.5 \mathrm{~mm}$ tip mapping and ablation catheter (Navistar, Biosense Webster, Diamond Bar, CA, USA) were used. An antral ablation line was created around each pair of ipsilateral pulmonary veins by application of point-by-point lesions using 25-30 $\mathrm{W}$ and an irrigation rate of $17-30 \mathrm{ml} / \mathrm{min}$.

For cryoballoon ablation, a $28 \mathrm{~mm}$ catheter (Arctic Front Advance, Medtronic Inc., Minneapolis, MN, USA) and an endoluminal spiral mapping catheter (Achieve, Medtronic) were used. For assessment of the exact position of the inflated cryoballoon catheter and optimal PV occlusion, contrast medium was administered. Target application time was $240 \mathrm{~s}$. For prevention of phrenic nerve injury, monitoring of diaphragmatic compound motor action potentials was conducted during phrenic nerve pacing throughout the ablation procedure. Diaphragmatic excursion was monitored by fluoroscopy and abdominal palpation. Ablation was terminated when the balloon temperature exceeded $-60^{\circ} \mathrm{C}$, esophageal temperature fell below $17^{\circ} \mathrm{C}$ or impairment of phrenic capture was observed.

\section{Statistical analysis}

Continuous variables are presented as mean \pm standard error of the mean (S.E.M.). Categorical variables are given as absolute or relative numbers. Normal distribution was analyzed using the Kolmogorov-Smirnov test. Student's $t$-test, Mann-Whitney or Wilcoxon signed rank tests were used as appropriate for continuous variables. Correlations between variables were assessed using the Pearson test. A $p$-value of $<0.05$ was considered statistically significant and denoted with asterisks $\left({ }^{*} p<0.05,{ }^{* *} p<0.01\right)$. Statistical analysis was performed using GraphPad Prism 6 (GraphPad Inc., La Jolla, CA, USA).

\section{Results}

\section{Patient characteristics and follow-up}

A detailed overview of clinical characteristics of the enrolled patients ( $n=10,50 \%$ men, $64 \pm 3$ years) is presented in Table I. The AF etiology was 
vagal in 5 patients and mixed adrenergic/vagal in 3 patients, whereas a clear classification was not possible in 2 patients. Mean follow-up time was $6.5 \pm 0.6$ months. One patient with a vagal driven arrhythmia suffered from AF recurrence and underwent a second AF ablation procedure 12 months after the first procedure. Two patients, initially suffering from vagal $A F$, without recurrence of $A F$, reported palpitations in the follow-up without an impact on physical activity (both EHRA I).

\section{PVI modulates HR and HRV}

The HR at rest increased following PVI (61 $\pm 2 \mathrm{bpm}$ vs. $77 \pm 3 \mathrm{bpm}, p<0.0001)$ in 10 out of $10 \mathrm{pa}$ tients. The intrinsic HR was different from the HR at rest ( $82 \pm 2$ bpm vs. $61 \pm 2$ bpm, $p<0.0001)$, but similar to the HR after PVI ( $82 \pm 2$ bpm vs. $77 \pm 3$ bpm, $p=0.147)$. HRV parameters of the time, frequency and nonlinear domain at rest were reduced after PVI (Table II). During follow-up (6.5 \pm 0.6 months), resting $H R$ remained elevated at a rate similar to that directly after ablation (76 $\pm 3 \mathrm{bpm}$ vs. $76 \pm 4 \mathrm{bpm}$, $p=0.796)$.

\section{$\mathrm{PVI}$ reduces RSA and HR dynamics during sympathetic/parasympathetic coactivation}

The RSA was diminished after PVI in all patients: The E/I difference (before PVI: $7.9 \pm 1.0$ vs. after PVI: $3.5 \pm 0.6 \mathrm{bpm}, p=0.006)$ and the $\mathrm{E} / \mathrm{l} \mathrm{ra}$ tio (before PVI: $1.14 \pm 0.02$ vs. after PVI: $1.05 \pm 0.01$, $p=0.003$ ) were reduced after PVI (Figures 1, 2).

The maximum HR response to sympathetic/ parasympathetic coactivation was diminished after PVI (before PVI: $10.2 \pm 0.7 \%$ vs. after PVI: 5.7 $\pm 1.1 \%, p=0.0144$; Figure $3 \mathrm{~A}$ ), with half of the patients showing a paradoxical HR increase. The maximum latency until the maximum $H R$ response was prolonged after PVI (before PVI: $29 \pm 8 \mathrm{~s}$ vs. after PVI: $77 \pm 8$ s, $p=0.003, n=9$ ).

The difference between the maximum HR change during sympathetic/parasympathetic coactivation before vs. after PVI correlated with the difference in RSA before vs. after PVI ( $\Delta E / I$ difference: $r=0.849, p=0.002 ; \Delta \mathrm{E} / \mathrm{I}$ ratio: $r=0.786$, $p=0.007$; Figures $3 \mathrm{~B}, \mathrm{C}$ ).

$\mathrm{PVI}$-induced changes in RSA ( $\Delta \mathrm{E} / \mathrm{l}$ difference, radiofrequency: $-4.2 \pm 2.2$ vs. cryoballoon: $-4.6 \pm 1.5 \mathrm{bpm}$, $p=0.886 ; \Delta \mathrm{E} / \mathrm{I}$ ratio: $-0.09 \pm 0.04$ vs. $-0.10 \pm 0.03$, $p=0.928)$ and HRV parameters ( $\triangle$ SDNN: -16 \pm 5 vs. $-18 \pm 9 \mathrm{~ms}, p=0.879 ; \Delta$ RMSSD: $-7 \pm 3$ vs. $-12 \pm 3 \mathrm{~ms}, p=0.282 ; \Delta$ pNN50 $-0.2 \pm 0.6$ vs. -2.4 $\pm 1.5 \%, p=0.207 ; \Delta$ LF: $-300 \pm 90$ vs. $-229 \pm 102 \mathrm{~ms}^{2}$, $p=0.615 ; \Delta \mathrm{HF}:-30 \pm 38$ vs. $-114 \pm 46 \mathrm{~ms}^{2}$, $p=0.199 ; \Delta$ LF/HF ratio: $-3.1 \pm 1.1$ vs. $-1.0 \pm 1.4$, $p=0.252 ; \Delta \mathrm{SD} 1:-4.8 \pm 2.3$ vs. $-8.3 \pm 2.1 \mathrm{~ms}$, $p=0.279 ; \Delta$ DFA1: $-0.38 \pm 0.12$ vs. $-0.20 \pm 0.22$, $p=0.491 ; \Delta$ REC: $4.8 \pm 7.1$ vs. $4.5 \pm 8.9 \%, p=0.979$;

Table II. Cardiac autonomic tone at rest in patients with paroxysmal AF before and after pulmonary vein isolation

\begin{tabular}{|c|c|c|c|}
\hline Parameter & Before PVI & After PVI & $P$-value \\
\hline \multicolumn{4}{|l|}{ Time domain: } \\
\hline $\mathrm{HR}[\mathrm{bpm}]$ & $61 \pm 2$ & $76 \pm 3$ & $<0.0001$ \\
\hline SDNN [ms] & $31 \pm 3$ & $14 \pm 3$ & 0.006 \\
\hline $\mathrm{RMSSD}[\mathrm{ms}]$ & $17 \pm 2$ & $8 \pm 2$ & 0.002 \\
\hline pNN50 (\%) & $2 \pm 1$ & $14 \pm 3$ & 0.004 \\
\hline \multicolumn{4}{|c|}{ Frequency domain: } \\
\hline $\mathrm{LF}\left[\mathrm{ms}^{2}\right]$ & $327 \pm 65$ & $63 \pm 33$ & 0.003 \\
\hline $\mathrm{HF}\left[\mathrm{ms}^{2}\right]$ & $117 \pm 25$ & $46 \pm 24$ & 0.049 \\
\hline $\mathrm{LF} / \mathrm{HF}$ & $3.2 \pm 0.7$ & $1.2 \pm 0.4$ & 0.050 \\
\hline \multicolumn{4}{|c|}{ Non-linear parameters: } \\
\hline $\mathrm{SD} 1[\mathrm{~ms}]$ & $12 \pm 1$ & $6 \pm 1$ & 0.002 \\
\hline REC (\%) & $33 \pm 3$ & $41 \pm 4$ & 0.408 \\
\hline DFA1 & $1.26 \pm 0.04$ & $0.97 \pm 0.10$ & 0.039 \\
\hline SampEn & $1.5 \pm 0.1$ & $1.3 \pm 0.1$ & 0.153 \\
\hline
\end{tabular}

Values are mean \pm S.E.M. Heart rate variability measurements are shown. Bold numbers denote significance. AF - atrial fibrillation, DFA1 - short-term fractal scaling exponent of the detrended fluctuation analysis, HF - high frequency, HR - heart rate, $L F-l o w$ frequency, pNN50 - NN50 count (number of pairs of adjacent normal-to-normal (NN) intervals differing by more than 50 ms in the entire recording) divided by the total number of all NN intervals, PVI - pulmonary vein isolation, REC - recurrence rate, RMSSD - square root of the mean squared differences of successive NN intervals, SampEn - sample entropy, SDNN - standard deviation of the NN interval, SD1 - sensitivities of short-term variability. 
A

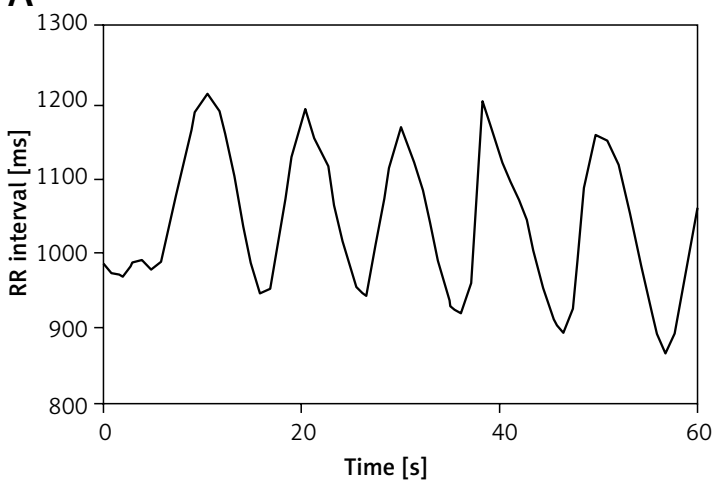

B

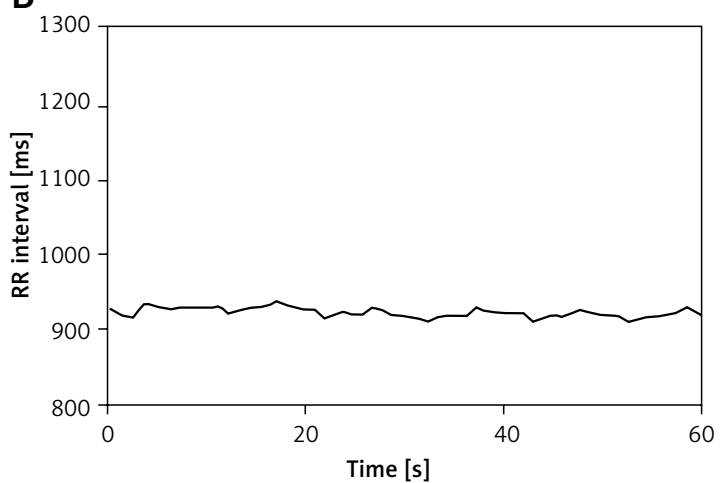

Figure 1. Change of heart rate variation during deep breathing before and after pulmonary vein isolation (PVI). Example curves during the deep breathing test demonstrating normal heart rate variation in a patient with paroxysmal atrial fibrillation before PVI (A). The heart rate response during the deep breathing test is diminished after PVI (B)

A

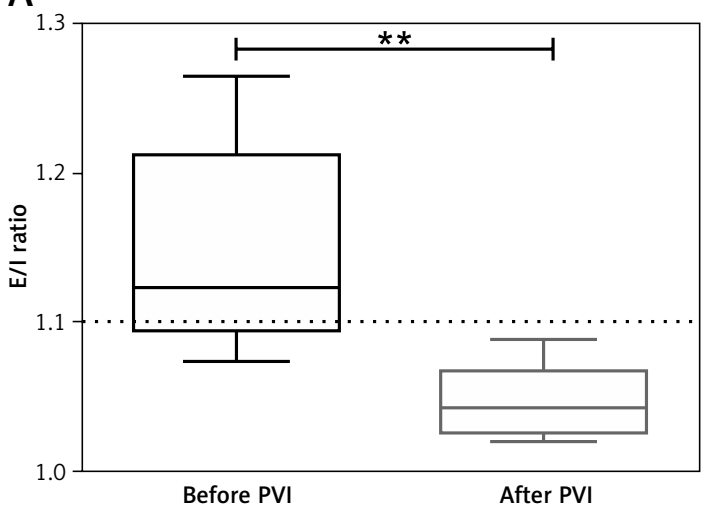

B

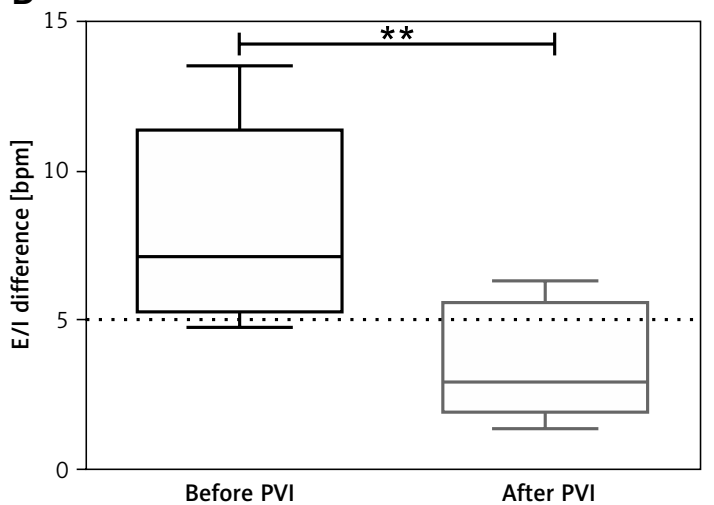

Figure 2. Respiratory sinus arrhythmia during deep breathing before and after pulmonary vein isolation (PVI). The $\mathrm{E} / \mathrm{I}$ ratio $(\mathrm{A})$ and $\mathrm{E} / \mathrm{I}$ difference $(\mathrm{B})$ diminished after $\mathrm{PVI}$. The dashed line depicts the limit for physiological values, which is $>1.1$ for the $E / I$ ratio and $>5 \mathrm{bpm}$ for the E/I difference. Asterisks denote significance $\left({ }^{* *} p<0.01\right)$

$\Delta$ SampEn: $-0.02 \pm 0.17$ vs. $-0.36 \pm 0.15, p=0.185$ ) did not differ between patients who were treated by using radiofrequency vs. cryoballoon ablation.

\section{Discussion}

The main finding of this study is that RSA is reduced after $\mathrm{PVI}$ in patients with paroxysmal AF. We found that this is related to a decrease in cardiac vagal tone as indicated by changes in HR and HRV following PVI. The PVI-related changes in RSA are correlated with those during sympathetic/ parasympathetic coactivation.

\section{RSA is reduced after PVI}

More than 2 decades ago RSA was found to improve the energy efficiency of pulmonary circulation by "saving heartbeats" [3]. Since then, various methods using spontaneous or controlled breathing have been used for RSA quantification and its use as a predictor for subsequent patient outcome [22].

We here demonstrate for the first time a significant reduction of RSA after PVI, which is related to the decrease in cardiac vagal tone, as supported by the observed changes of resting HR and HRV in our patients. Supporting this, RSA is known to be reduced after atropine application in healthy humans $[23,24]$ and is modulated in diseases such as diabetic autonomic neuropathy $[25,26]$. Although RSA also depends on feedback regulation such as chemoreceptors [27] and pulmonary afferents and is further modulated by central respiratory drive [28-32], the direct cardiac influence and the related decrease in intracardiac vagal control following PVI seem to be key in our patients.

\section{Cardiac vagal tone is decreased after PVI}

An increased HR and diminished HRV after PVI are widely recognized to result from the withdrawal of cardiac vagal activity induced by the inevitable obliteration of cholinergic intracardiac neurons during ablation [33]. In this study relevant HRV parameters were diminished after $\mathrm{PVI}$, which is in line with previous findings [11, 34-36]. Although cryoballoon ablation has been reported to induce greater tissue damage [37], HRV parameters were similarly reduced compared with RF ablation. 
A

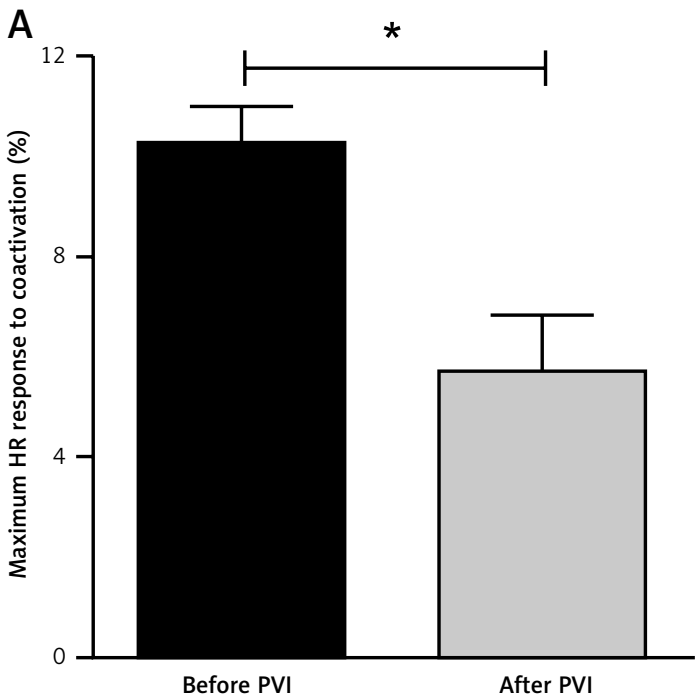

\section{c}

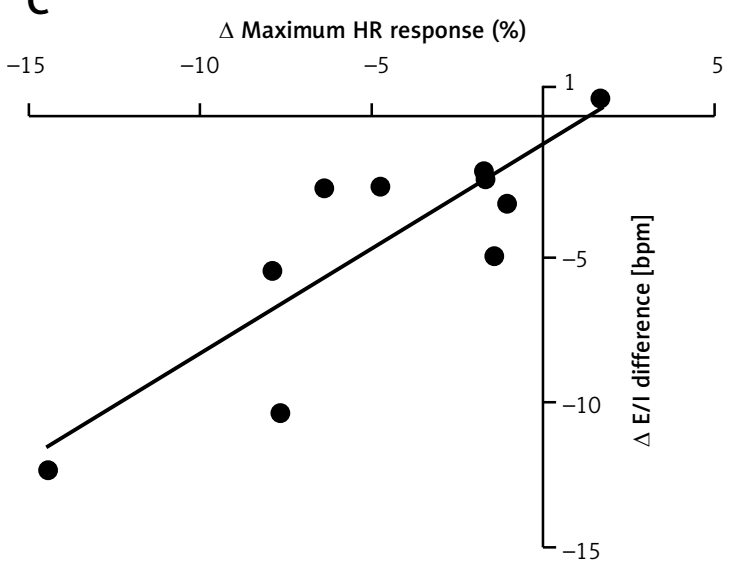

Besides RSA, the diminished maximum HR response to sympathetic/parasympathetic coactivation and the increase in maximum latency after PVI indicate an impairment of the trigeminal-brainstem-vagal reflex and vagal activity $[17,38]$. Similar observations have been made after vagotomy, pharmacological cholinergic blockade and in patients with brainstem stroke as well as in patients with amyotrophic lateral sclerosis [16, 39].

Tonic vagal activity describes the basal cardiac vagal activity during rest and is measured using HRV parameters $[19,40]$. Basal phasic vagal activity describes the phasic activity at rest of the autonomic nervous system, which can be analyzed using RSA [41]. Although tonic vagal activity seems to be related to phasic vagal control [42], no relation between phasic tone and sympathetic/ parasympathetic coactivation has been described before. The PVI-induced changes in RSA in our patients correlated with those during sympathetic/ parasympathetic coactivation. This is important since cholinergic and adrenergic neurons and their axons are highly collocated at the pulmonary vein-atrial junction.

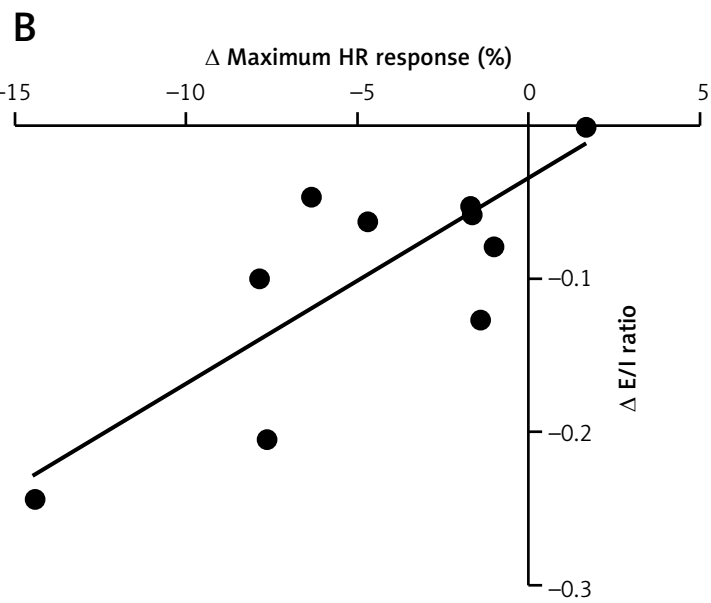

Figure 3. Correlation between heart rate (HR) change during sympathetic/parasympathetic coactivation and modulated RSA parameters. A - The maximum HR response during sympathetic/parasympathetic coactivation was reduced after pulmonary vein isolation (PVI). B, C - The PVI-induced alterations in RSA correlated with the HR changes during sympathetic/parasympathetic coactivation

In addition, in patients with comorbidities involving sinus nodal or left ventricular function, additional hemodynamic and/or electrophysiological adaptations might impact patient outcome since both the extrinsic $[43,44]$ and intrinsic [45] cardiac neural network are well known to modulate cardiac electrophysiology at different levels within the hierarchy of the autonomic nervous system.

Targeted ablation of ganglionated plexi is under investigation for symptomatic bradycardia including cardioinhibitory syncope $[46,47]$. As the autonomic nervous system and ganglionated plexi are inevitably modulated during PVI, one might speculate whether intermittent bradycardia or left ventricular sympathetic control can be diminished by PVI. However, this might still result in sympathetic/parasympathetic imbalance due to the colocalization of cholinergic and adrenergic neurons.

\section{Clinical implications}

The latest consensus statement on catheter and surgical ablation of AF emphasizes the potential side effects of PVI including transient and 
permanent alterations in $\mathrm{HR}$ [10]. Elevation of $\mathrm{HR}$, inappropriate sinus tachycardia and reduction of HRV are well described after PVI, but are in most cases not associated with significant symptoms.

Currently, exercise performance [48] in patients with AF following catheter ablation has not been fully explored: On the one hand, in patients with longstanding asymptomatic persistent AF catheter ablation improved exercise performance [49]. On the other hand, HR recovery as well as chronotropic reserve has been found to be reduced in patients with paroxysmal AF for at least up to 3 months after PVI [50]. One might speculate that the latter is linked to reduced exercise performance even after successful restoration of sinus rhythm, especially considering our findings.

This is relevant since although most autonomic alterations associated with PVI are transient, some of these changes can last for over a year [51, 52]. In addition, the deep breathing test used here can be implemented as a relatively simple bedside test. Currently, PVI-induced changes are mostly assessed using specific parameters measured during the ablation procedure. Changes in HR, in the cycle length at which $1: 1$ conduction over the atrioventricular node stops (Wenckebach cycle length) and in the interval describing the time between the first atrial and His bundle deflection (AH interval), associated with a negative response to atropine, have been considered as immediate end points of those procedures [47]. However, positioning of catheters is necessary to investigate these parameters, which might be influenced by sedation and pain medication during the procedure. Therefore, evaluation of RSA using the deep breathing test before and after the procedure might be useful to evaluate safety and success of targeted or accidental cardiac autonomic denervation during follow-up.

\section{Limitations}

This proof-of-concept study, presenting the first evidence that RSA is reduced after PVI as a result of decreased cardiac vagal control, has several limitations that need to be addressed: First, this is a single-center study with a small number of patients. However, RSA is a strong physiological signal and the marked changes in $H R, H R V$, and RSA following PVI support our study design. This is in line with another study having investigated targets and end points in cardiac autonomic denervation procedures in 14 patients including right and left atrial procedures [47].

Next, we here focused on the acute effect of PVI on RSA and its relation to cardiac vagal control. The RSA has not been investigated during follow-up. How RSA is related to exercise capacity in patients with AF was beyond the aim of the pres- ent study. No conclusions can be drawn from the present study how the decrease in RSA impacts exercise capacity [53] and patient outcome during long-term follow-up.

In addition, related pathomechanisms and their potential clinical implications, especially in patients with various comorbidities including heart failure, need to be studied in detail. Although the sympathetic neuronal tone is upregulated in heart failure, there is a paradoxical reduction in norepinephrine synthesis and reuptake in the cardiac sympathetic nervous system as well as a cholinergic transdifferentiation of cardiac sympathetic nerves [54]. Therefore, our findings support the need for future studies investigating the importance of changes in RSA and its clinical relevance in patients with AF following PVI during long-term follow-up.

In conclusion, RSA is reduced after PVI in patients with paroxysmal AF. Our findings suggest that this is related to the decrease in cardiac vagal tone after PVI. Whether this affects clinical outcomes including patients' exercise capacity needs to be investigated.

\section{Acknowledgments}

Christiane Jungen and Fares-Alexander Alken have contributed equally to this work.

\section{Conflict of interest}

The authors declare no conflict of interest.

\section{References}

1. Japundzic N, Grichois ML, Zitoun P, Laude D, Elghozi JL. Spectral analysis of blood pressure and heart rate in conscious rats: effects of autonomic blockers. J Auton Nerv Syst 1990; 30: 91-100.

2. Ludwig C. Beiträge zur Kenntnis des Einflusses der Respirationsbewegung auf den Blutlauf im Aortensystem. Arch Anat Physiol 1847; 13: 242-302.

3. Hayano J, Yasuma F, Okada A, Mukai S, Fujinami T. Respiratory sinus arrhythmia. A phenomenon improving pulmonary gas exchange and circulatory efficiency. Circulation 1996; 94: 842-7.

4. Ben-Tal A, Shamailov SS, Paton JF. Evaluating the physiological significance of respiratory sinus arrhythmia: looking beyond ventilation-perfusion efficiency. J Physiol 2012; 590: 1989-2008.

5. Toska K, Eriksen M. Respiration-synchronous fluctuations in stroke volume, heart rate and arterial pressure in humans. J Physiol 1993; 472: 501-12.

6. Perkiomaki J, Ukkola O, Kiviniemi A, et al. Heart rate variability findings as a predictor of atrial fibrillation in middle-aged population. J Cardiovasc Electrophysiol 2014; 25: 719-24.

7. Agarwal SK, Norby FL, Whitsel EA, et al. Cardiac autonomic dysfunction and incidence of atrial fibrillation: results from 20 years follow-up. J Am Coll Cardiol 2017; 69: 291-9.

8. Guazzi M, Belletti S, Tumminello G, Fiorentini C, Guazzi MD. Exercise hyperventilation, dyspnea sensation, 
and ergoreflex activation in lone atrial fibrillation. Am J Physiol Heart Circ Physiol 2004; 287: H2899-905.

9. Wickramasinghe SR, Patel VV. Local innervation and atrial fibrillation. Circulation 2013; 128: 1566-75.

10. Calkins H, Hindricks G, Cappato R, et al. 2017 HRS/ EHRA/ECAS/APHRS/SOLAECE expert consensus statement on catheter and surgical ablation of atrial fibrillation: executive summary. J Interv Card Electrophysiol 2017; 50: 1-55.

11. Eickholt C, Jungen C, Drexel T, et al. Sympathetic and parasympathetic coactivation induces perturbed heart rate dynamics in patients with paroxysmal atrial fibrillation. Med Sci Monit 2018; 24: 2164-72.

12. European Heart Rhythm Association, European Association for Cardio-Thoracic Surgery, Camm AJ, et al. Guidelines for the management of atrial fibrillation: The Task Force for the Management of Atrial Fibrillation of the European Society of Cardiology (ESC). Eur Heart J 2010; 31: 2369-429.

13. Tulppo MP, Kiviniemi AM, Hautala AJ, et al. Physiologica background of the loss of fractal heart rate dynamics. Circulation 2005; 112: 314-9.

14. Hilz MJ, Dutsch M. Quantitative studies of autonomic function. Muscle Nerve 2006; 33: 6-20.

15. Hilz MJ, Stemper B, Sauer P, Haertl U, Singer W, Axelrod FB. Cold face test demonstrates parasympathetic cardiac dysfunction in familial dysautonomia. Am J Physiol 1999; 276: R1833-9.

16. Khurana RK, Watabiki S, Hebel JR, Toro R, Nelson E. Cold face test in the assessment of trigeminal-brainstem-vagal function in humans. Ann Neurol 1980; 7: 144-9.

17. Khurana RK, Wu R. The cold face test: a non-baroreflex mediated test of cardiac vagal function. Clin Auton Res 2006; 16: 202-7.

18. Tarvainen MP, Niskanen JP, Lipponen JA, Ranta-Aho PO, Karjalainen PA. Kubios HRV: heart rate variability analysis software. Comput Methods Programs Biomed 2014; 113: 210-20.

19. Heart rate variability: standards of measurement, physiological interpretation and clinical use. Task Force of the European Society of Cardiology and the North American Society of Pacing and Electrophysiology. Circulation 1996; 93: 1043-65.

20. Jose AD, Collison D. The normal range and determinants of the intrinsic heart rate in man. Cardiovasc Res 1970; 4: 160-7.

21. Gunawardene MA, Hoffmann BA, Schaeffer B, et al. Influence of energy source on early atrial fibrillation recurrences: a comparison of cryoballoon vs. radiofrequency current energy ablation with the endpoint of unexcitability in pulmonary vein isolation. Europace 2018; 20: 43-49.

22. Sinnecker D, Dommasch M, Steger A, et al. Expirationtriggered sinus arrhythmia predicts outcome in survivors of acute myocardial infarction. J Am Coll Cardiol 2016; 67: 2213-20.

23. Lacroix D, Logier R, Kacet S, Hazard JR, Dagano J, Lekieffre J. Effects of consecutive administration of central and peripheral anticholinergic agents on respiratory sinus arrhythmia in normal subjects. J Auton Nerv Syst 1992; 39: 211-7.

24. Araujo CG, Nobrega AC, Castro CL. Heart rate responses to deep breathing and 4-seconds of exercise before and after pharmacological blockade with atropine and propranolol. Clin Auton Res 1992; 2: 35-40.

25. Wheeler T, Watkins PJ. Cardiac denervation in diabetes. Br Med J 1973; 4: 584-6.
26. Smith SA. Reduced sinus arrhythmia in diabetic autonomic neuropathy: diagnostic value of an age-related normal range. Br Med J (Clin Res Ed) 1982; 285: 1599-601.

27. Drexel T, Eickholt C, Muhlsteff J, et al. Vagal heart rate control in patients with atrial fibrillation: impact of tonic activation of peripheral chemosensory function in heart failure. Adv Exp Med Biol 2013; 755: 287-97.

28. Al-Ani M, Forkins AS, Townend JN, Coote JH. Respiratory sinus arrhythmia and central respiratory drive in humans. Clin Sci 1996; 90: 235-41.

29. Jewett DL. Activity of single efferent fibres in the cervical vagus nerve of the dog, with special reference to possible cardio-inhibitory fibres. J Physiol 1964; 175: 321-57.

30. Kunze DL. Reflex discharge patterns of cardiac vagal efferent fibres. J Physiol 1972; 222: 1-15.

31. McAllen RM, Spyer KM. Two types of vagal preganglionic motoneurones projecting to the heart and lungs. J Physiol 1978; 282: 353-64.

32. Taha BH, Simon PM, Dempsey JA, Skatrud JB, Iber C. Respiratory sinus arrhythmia in humans: an obligatory role for vagal feedback from the lungs. J Appl Physiol 1995; 78: 638-45

33. Jungen C, Scherschel K, Eickholt C, et al. Disruption of cardiac cholinergic neurons enhances susceptibility to ventricular arrhythmias. Nat Commun 2017; 8: 14155.

34. Seaborn GE, Todd K, Michael KA, et al. Heart rate variability and procedural outcome in catheter ablation for atrial fibrillation. Ann Noninvasive Electrocardiol 2014; 19: 23-33.

35. Oswald H, Klein G, Koenig T, Luesebrink U, Duncker D, Gardiwal A. Cryoballoon pulmonary vein isolation temporarily modulates the intrinsic cardiac autonomic nervous system. J Interv Card Electrophysiol 2010; 29: 57-62.

36. Pappone C, Santinelli V, Manguso F, et al. Pulmonary vein denervation enhances long-term benefit after circumferential ablation for paroxysmal atrial fibrillation. Circulation 2004; 109: 327-34.

37. Aryana A, Singh SM, Mugnai G, et al. Pulmonary vein reconnection following catheter ablation of atrial fibrillation using the second-generation cryoballoon versus open-irrigated radiofrequency: results of a multicenter analysis. J Interv Card Electrophysiol 2016; 47: 341-8.

38. Panneton WM, McCulloch PF, Sun W. Trigemino-autonomic connections in the muskrat: the neural substrate for the diving response. Brain Res 2000; 874: 48-65.

39. Tutaj M, Miller M, Tomik B, et al. Sympathetic vascular response to facial cooling is increased in flail phenotypes of amyotrophic lateral sclerosis. Amyotroph Lateral Scler Frontotemporal Degener 2017; 5: 1-9.

40. Ciesielczyk K, Furgala A, Dobrek L, Juszczak K, Thor P. Altered sympathovagal balance and pain hypersensitivity in TNBS-induced colitis. Arch Med Sci 2017; 13: 246-55.

41. Shields RW Jr. Heart rate variability with deep breathing as a clinical test of cardiovagal function. Cleve Clin J Med 2009; 76 Suppl 2: S37-40.

42. Park G, Vasey MW, Van Bavel JJ, Thayer JF. When tonic cardiac vagal tone predicts changes in phasic vagal tone: the role of fear and perceptual load. Psychophysiology 2014; 51: 419-26.

43. Meyer C, Rana OR, Saygili E, et al. Hyperoxic chemoreflex sensitivity is impaired in patients with neurocardiogenic syncope. Int J Cardiol 2010; 142: 38-43.

44. Mehlsen J, Kaijer MN, Mehlsen AB. Autonomic and electrocardiographic changes in cardioinhibitory syncope. Europace 2008; 10: 91-5.

45. Meyer C, Rana OR, Saygili E, et al. Augmentation of left ventricular contractility by cardiac sympathetic neural stimulation. Circulation 2010; 121: 1286-94. 
46. Pachon JC, Pachon EI, Pachon JC, et al. "Cardioneuroablation": new treatment for neurocardiogenic syncope, functional AV block and sinus dysfunction using catheter RF-ablation. Europace 2005; 7: 1-13.

47. Rivarola EW, Hachul D, Wu T, et al. Targets and end points in cardiac autonomic denervation procedures. Circ Arrhythm Electrophysiol 2017; 10: e004638.

48. Kim J, Al-Mallah M, Juraschek SP, et al. The association of clinical indication for exercise stress testing with allcause mortality: the FIT Project. Arch Med Sci 2016; 12: 303-9.

49. Mohanty S, Santangeli P, Mohanty P, et al. Catheter ablation of asymptomatic longstanding persistent atrial fibrillation: impact on quality of life, exercise performance, arrhythmia perception, and arrhythmia-free survival. J Cardiovasc Electrophysiol 2014; 25: 1057-64.

50. Kuyumcu MS, Ozeke O, Cay S, et al. The short-term im pact of the catheter ablation on noninvasive autonomic nervous system parameters in patients with paroxysmal atrial fibrillation. Pacing Clin Electrophysiol 2017; 40: 1193-9.

51. Kang KW, Kim TH, Park J, et al. Long-term changes in heart rate variability after radiofrequency catheter ablation for atrial fibrillation: 1-year follow-up study with irrigation tip catheter. J Cardiovasc Electrophysiol 2014; 25: 693-700.

52. Qin M, Liu X, Jiang WF, Wu SH, Zhang XD, Po S. Vagal response during pulmonary vein isolation: re-recognized its characteristics and implications in lone paroxysmal atrial fibrillation. Int J Cardiol 2016; 211: 7-13.

53. Porta A, Barrabes JA, Candell-Riera J, et al. Plasma B-type natriuretic peptide levels are poorly related to the occurrence of ischemia or ventricular arrhythmias during symptom-limited exercise in low-risk patients. Arch Med Sci 2016; 12: 341-8.

54. Kanazawa H, leda M, Kimura K, et al. Heart failure causes cholinergic transdifferentiation of cardiac sympathetic nerves via gp130-signaling cytokines in rodents. J Clin Invest 2010; 120: 408-21. 